\title{
Article \\ Effects of 8 Weeks of High-Intensity Interval Training and Spirulina Supplementation on Immunoglobin Levels, Cardio-Respiratory Fitness, and Body Composition of Overweight and Obese Women
}

\author{
Hadi Nobari ${ }^{1,2,3, * \mathbb{D}}$, Elham Eyni Gandomani ${ }^{3}$, Jalil Reisi ${ }^{3, * \mathbb{D}}$, Reyhaneh Vahabidelshad ${ }^{4}$, Katsuhiko Suzuki ${ }^{5}$, \\ Stella Lucia Volpe ${ }^{6}$ and Jorge Pérez-Gómez ${ }^{7}$ (D) \\ 1 Department of Exercise Physiology, Faculty of Educational Sciences and Psychology, \\ University of Mohaghegh Ardabili, Ardabil 56199-11367, Iran \\ 2 Department of Physiology, School of Sport Sciences, University of Extremadura, 10003 Cáceres, Spain \\ 3 Department of Exercise Physiology, Faculty of Sport Sciences, University of Isfahan, Isfahan 81746-7344, Iran; \\ elham_eynii@yahoo.com \\ 4 Faculty of Motor Sciences, Université Libre de Bruxelles, 1070 Brussels, Belgium; reyhanevahabi@yahoo.com \\ 5 Faculty of Sport Sciences, Waseda University, Saitama 359-1192, Japan; katsu.suzu@waseda.jp \\ 6 Department of Human Nutrition, Foods and Exercise, Virginia Polytechnic Institute and State University, \\ Blacksburg, VA 24061, USA; stellalv@vt.edu \\ 7 HEME Research Group, Faculty of Sport Sciences, University of Extremadura, 10003 Cáceres, Spain; \\ jorgepg100@gmail.com \\ * Correspondence: hadi.nobari1@gmail.com (H.N.); jalil_reisi@yahoo.com (J.R.)
}

check for

updates

Citation: Nobari, H.; Gandomani,

E.E.; Reisi, J.; Vahabidelshad, R.;

Suzuki, K.; Volpe, S.L.; Pérez-Gómez,

J. Effects of 8 Weeks of High-Intensity Interval Training and Spirulina Supplementation on Immunoglobin Levels, Cardio-Respiratory Fitness, and Body Composition of Overweight and Obese Women Biology 2022, 11, 196. https:// doi.org/10.3390/biology11020196

Received: 28 December 2021

Accepted: 24 January 2022

Published: 26 January 2022

Publisher's Note: MDPI stays neutral with regard to jurisdictional claims in published maps and institutional affiliations.

Copyright: (C) 2022 by the authors. Licensee MDPI, Basel, Switzerland. This article is an open access article distributed under the terms and conditions of the Creative Commons Attribution (CC BY) license (https:// creativecommons.org/licenses/by/ $4.0 /)$.
Simple Summary: Overweight and obese, like other forms of malnutrition, have been shown to affect immune function through changing immunoglobin or cardio-respiratory fitness levels and cell-mediated immune responses. Although calorie restriction and exercise are the most common therapies for obesity or overweight, it is unclear what kind of supplementation these people should take or how much exercise they should perform. Hence, in this study, we examined the effect of 8 weeks of high-intensity interval training (HIIT) with spirulina supplementation on the humoral immunity, cardio-respiratory fitness, and body composition of overweight and obese women. The results demonstrated that spirulina supplementation with HIIT not only decreased fat free mass but also boosted immunoglobin-A, which plays an important role in the immune system.

Abstract: Our study examined the effect of 8 weeks of high-intensity interval training (HIIT) and spirulina supplementation on the humoral immunity, cardio-respiratory fitness, and body composition of overweight and obese women. Thirty sedentary women (height: $161.7 \pm 2.8 \mathrm{~cm}$, body mass: $75.8 \pm 8.4 \mathrm{~kg}$, body mass index [BMI]: $28.8 \pm 2.5 \mathrm{~kg} / \mathrm{m}^{2}$, age: $25.1 \pm 6.7$ years) were divided into three groups: placebo with HIIT group, spirulina group (SG), or combined group (CG). Exercise groups performed HIIT for 8 weeks, with three sessions per week and four to seven repetitions in each session of $30 \mathrm{~s}$ running and $30 \mathrm{~s}$ walking; the intensity was established at $90 \%$ of the maximum heart rate. Supplementation groups received $6 \mathrm{~g}$ of spirulina powder per day. Fasting blood samples were collected before and after 8 weeks to determine the concentrations of immunoglobulins ( $\operatorname{Ig} \mathrm{A}$ and $\mathrm{IgG}$ ). There was a significant group-by-time interaction for fat free mass (FFM; $p=0.001, \mathrm{f}=8.52$, $\left.\eta \mathrm{p}^{2}=0.39\right)$ and $\operatorname{IgA}\left(p=0.036, \mathrm{f}=3.86, \eta \mathrm{p}^{2}=0.22\right)$. The post hoc analysis revealed that $\mathrm{CG}$ reduced FFM significantly ( $p=0.012, g=-0.55)$ after training. CG and SG showed significantly greater IgA concentrations after 8 weeks ( $p=0.02, g=0.70$ and $p=0.001, g=0.34$, respectively). We conclude that spirulina supplementation with HIIT affects the body composition (lower FFM) but also boosts IgA, which plays an important role in the immune system.

Keywords: antioxidant; body fat; IgA; immunomodulation; nutritional supplement; obesity; physical activity 


\section{Introduction}

Overweight and obesity refer to the abnormal or excessive accumulation of fat that may lead to an increased risk of chronic disease. The World Health Organization (WHO) defines a body mass index (BMI) $\geq 25 \mathrm{~kg} / \mathrm{m}^{2}$ as overweight and a BMI $\geq 30 \mathrm{~kg} / \mathrm{m}^{2}$ as obesity [1,2]. Research has shown that, with each unit of increase in BMI, the risk of cardiovascular disease increases by $8 \%$. However, for each unit of a metabolic equivalent task increase in physical activity, the risk of cardiovascular disease decreases. Excess body fat is a condition associated with an impaired immune system and greater susceptibility to developing an infectious disease [3-5].

Spirulina maxima is used as a nutritional supplement because of its phytochemical content (phenolic compounds, carotenoids, and tocopherols) and essential nutrients (proteins, $n-3$ and $n-6$ fatty acids) [6,7]. It has been suggested that spirulina might help to increase lean body mass because of its high protein content, particularly of the branched-chain amino acids, leucine, valine, and isoleucine. As a result of this, athletes have used spirulina to improve the body composition and physical performance [8,9]. Among the species of spirulina that are safe for consumption are Spirulina maxima, arthrospira fusiformis, and platensis, and the latter is the most commonly used and studied in the scientific literature [10]. As previously stated, spirulina has a high protein content (50\% to $70 \%$ of its dry weight) [11], all of the essential amino acids, most of the vitamins and minerals, and it confers numerous health benefits, such as antioxidant, immunomodulatory, anti-inflammatory, and antiviral activities $[7,12]$. Many athletes have consumed spirulina for these health benefits, and it was suggested that the Chinese and Cuban Olympic teams consumed spirulina daily for many years to improve their athletic performance [13]. Hernández-Lepe et al. gave $4.5 \mathrm{~g}$ of spirulina per day to their participants for six weeks [14].

High-intensity interval training (HIIT), which is alternating between periods of high intensity and recovery, has become a popular training method due to its time efficiency. HIIT is effective for improving fasting blood glucose concentrations and reducing blood pressure in overweight or obese populations $[15,16]$. Recent studies have clearly shown that intense intermittent exercise is better for reducing fat than endurance exercise [17-19]. In addition, HIIT has been shown to reduce blood pressure in individuals who are overweight or obese [20]. HIIT has been shown to have benefits in young and older individuals on body weight, the regulation of physiological parameters such as blood pressure, improvement in aerobic capacity as measured by maximum oxygen consumption $\left(\mathrm{VO}_{2 \max }\right)$, and reductions in glucose and triglyceride concentrations and fat free mass, with an increased lower limb muscle power [21]. HIIT is also effective for improving fasting glucose concentrations and reducing blood pressure in individuals who are overweight or obese [22]. In a study of 20 healthy untrained overweight/obese males, the following 12 weeks of HIIT reported that the BMI and fat mass percentage were significantly decreased [23]. HIIT also increase cardiopulmonary fitness. The best indicator for assessing cardiorespiratory fitness is the measurement of $\mathrm{VO}_{2 \max }$ [24]. Gillen et al. [25] showed that short-term low-volume HIIT is a time-efficient strategy to improve the body composition and muscle oxidative capacity in women who are overweight or obese. In addition, Andreato et al. [26] reported that HIIT can be used as a secondary method for the treatment of obesity in adults.

The immune system contains complex mechanisms that are of particular importance in the body's defense against pathogenic microorganisms, bacteria, parasites, and viruses. The immune system is divided into two arms: innate immunity (natural or non-special) and adaptive immunity (acquired or special), where the acquired immunity is divided into humoral and cellular parts. Cellular immunity includes T cells (e.g., $\mathrm{CD}_{8}, \mathrm{CD}_{4}$, and $\mathrm{CD}_{3}$ ) and $\mathrm{B}$ cells (e.g., $\mathrm{CD}_{22}, \mathrm{CD}_{20}$, and $\mathrm{CD}_{19}$ ). Humoral immunity includes immunoglobulins (e.g., $\operatorname{IgM}, \operatorname{IgA}, \operatorname{IgD}, \operatorname{IgE}$, and $\operatorname{IgG}$ ) [27]. IgA is the major immunoglobulin in mucous secretions, such as saliva and tears, and it is thought to provide a front line of defense against pathogens and antigens present on mucosal surfaces, such as the airways. IgA is able to inhibit the binding of viruses and bacteria to the mucosal epithelium and viral replication [28]. Controversial results have been observed regarding the impact of HIIT 
on the immune system. The majority of the studies have shown that HIIT suppressed the immune system, whereas others have reported that this training did not affect the immune system $[27,29,30]$. In a few cases, it has been reported that HIIT improved immune function [31,32]. IgG is vital for the proper functioning of the body's defense system, staying healthy, and fighting pathogens [33]. Owen et al. [34] showed that high-intensity soccer training might cause a significant decrease in s-IgA values post-exercise compared to low-intensity training. Lee et al. [35] indicated that there was a reduced trend of IgA in male adults after 12 weeks of judo training alone, or combined with resistance training or with interval training. The initial laboratory examination of humoral immunity consists of measuring the levels of various immunoglobulin (IgG and IgA) in serum [36]. The mean values for IgG were from 720 to $1038 \mathrm{mg} / 100 \mathrm{~mL}$ in the females that we can compare with our study [37]. In our study, overweight and obese women were recruited because there are few studies about HIIT and spirulina supplementation on the humoral immune system, cardio-respiratory fitness, and body composition in this population. Therefore, we hypothesized that 8 weeks of HIIT and spirulina supplementation could affect the humoral immune system, $\mathrm{VO}_{2 \mathrm{max}}$, and body composition in overweight and obese women.

\section{Materials and Methods}

\subsection{Participants}

Thirty women (mean \pm standard deviation); $25.1 \pm 6.7$ years of age; height: $161.7 \pm 2.8 \mathrm{~cm}$, body mass: $75.8 \pm 8.4 \mathrm{~kg}$; with a BMI between 25 to $35 \mathrm{~kg} / \mathrm{m}^{2}$, were divided into three groups: placebo with HIIT (PH, $n=10)$, spirulina group (SG, $n=10)$, and combined group (CG, $n=10$ ). PH performed HIIT for 8 weeks, 3 sessions per week, and received a placebo per day. SG received $6 \mathrm{~g}$ of spirulina powder per day and did not participate in any regular training. CG performed the same HIIT and received $6 \mathrm{~g}$ of spirulina powder per day [38]. Exclusion and enrollment criteria for all groups were: (1) participants who were physically active; (2) participants who were on a weight loss diet; (3) participants with medical conditions for physical activity; (4) participants with a BMI lower than 25 or above $35 \mathrm{~kg} / \mathrm{m}^{2}$; (5) they should not have any specific illness or diet; (6) those who missed more than three practice sessions were excluded from the study (Figure 1). All participants signed and accepted the informed consent according to the recommendations of the Helsinki Declaration for Human Research. Our study is a part of the master's thesis of the University of Isfahan registered with the code IR.UI.REC.1397.145.

Within $24 \mathrm{~h}$ following the treatment, subjects were advised not to ingest alcohol, caffeine, theine, hot liquids, or smoke. In addition, subjects were advised not to ingest medications, performance-enhancing capsules, or other supplements during the study [39]. We instructed the participants to maintain their usual dietary intake and not to lower their energy intake, and also asked them to maintain their usual physical activity during the study [40]. Based on the recommendation, participants maintained their usual dietary intake and physical activity levels.

\subsection{Sample Size}

Using the statistical method investigated and G-Power software (University of Dusseldorf, Dusseldorf, Germany), we calculated the design's power and sample size. This included the following: a priori and F tests are used to calculate the achieved power; ANOVA: repeated measurements, within-interaction analysis; err prob for $\alpha=0.05$; minimum effect size $=0.35$; number of groups $=3$; number of measures $=2$; and err prob for $1-\beta=0.80$. With real or actual power, there is an $82.2 \%$ chance of successfully rejecting the null hypothesis of no difference in variables in the study with 24 participants. 


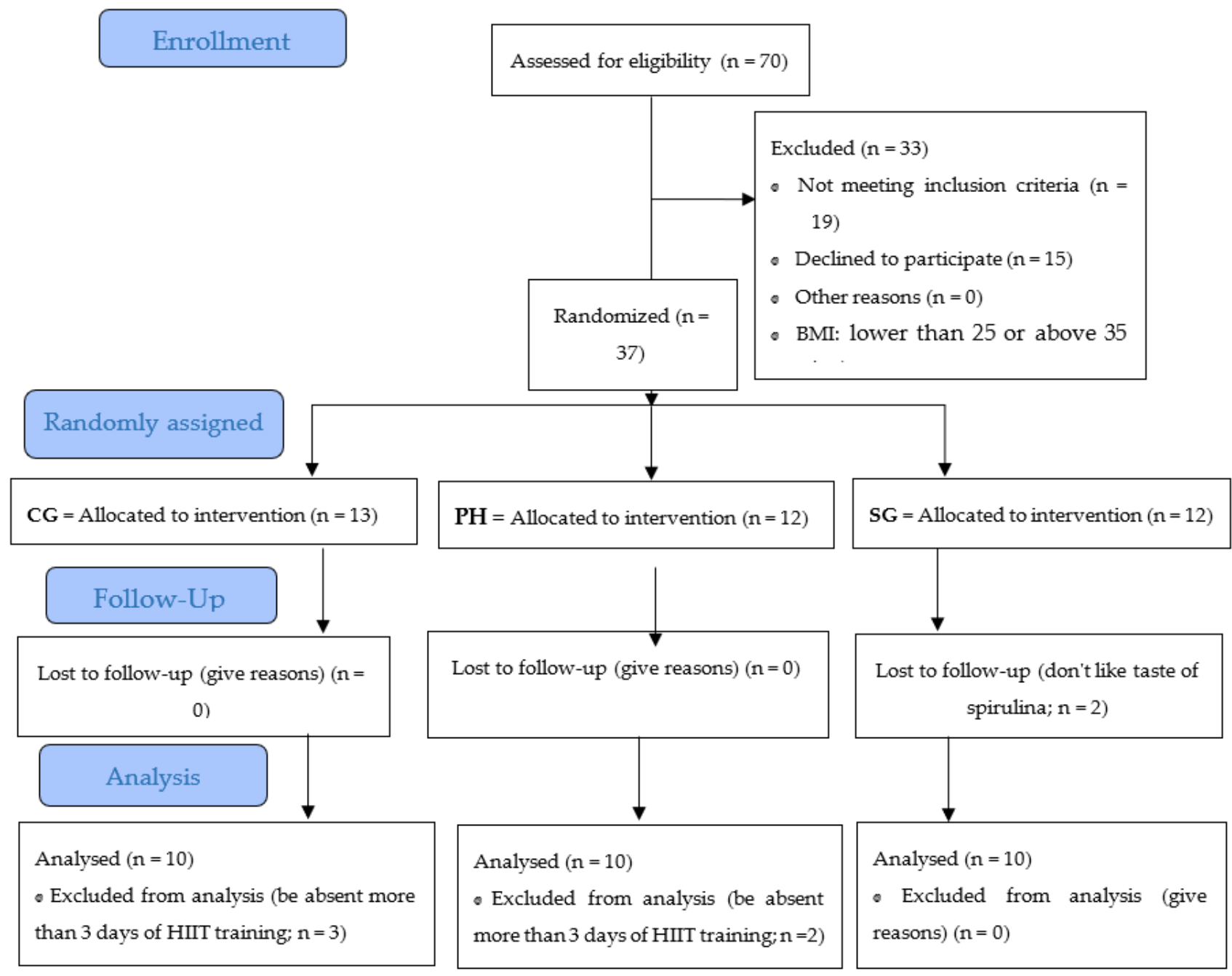

Figure 1. Flow diagram of how to enter, experimental course, and analysis of participants. Abbreviation; $\mathrm{PH}=$ placebo and high-intensity interval training (HIIT); $\mathrm{CG}=$ combined group (spirulina and HIIT); SG = spirulina group; $\mathrm{BMI}=$ body mass index.

\subsection{Experimental Approach to the Problem}

This research was a quasi-experimental, double-blinded design with baseline and post-intervention measurements. Before starting the research, age, height, and BMI were assessed (Table 1), and BF\% was measured by the thickness of the subcutaneous fat layer using skinfold analysis. In the next stage, participants performed a shuttle run test to assess aerobic fitness according to guidelines [41] of $\mathrm{VO}_{2 \max }$ measurement. Participants received oral and written information about supplement. Blood samples were collected at two different time points: before and after the supplementation and training periods. The samples were transferred to the laboratory immediately after each collection and centrifuged there. 
Table 1. Characteristics of the participants.

\begin{tabular}{|c|c|c|c|c|c|}
\hline Group & Age (Year) & Height (cm) & Body Mass (kg) & BMI $\left(\mathrm{kg} / \mathrm{m}^{2}\right)$ & $90 \% \mathrm{HR}_{\max }$ \\
\hline PH & $26 \pm 8$ & $162 \pm 4$ & $73 \pm 5$ & $27.6 \pm 1.9$ & 171 bpm \\
\hline CG & $24 \pm 6$ & $163 \pm 3$ & $76 \pm 11$ & $28.8 \pm 4.3$ & $\sim 172$ bpm \\
\hline SG & $24 \pm 6$ & $160 \pm 2$ & $77 \pm 9$ & $29.9 \pm 1.2$ & $\sim 172$ bpm \\
\hline
\end{tabular}

Data are presented in mean \pm standard deviation. Abbreviation: $\mathrm{PH}=$ placebo and high-intensity interval training (HIIT); $C G$ = combined group (spirulina and HIIT); $S G$ = spirulina group; BMI = body mass index; $90 \% \mathrm{HR}_{\max }=90 \%$ of maximum heart rate; $\mathrm{bpm}=$ beats per minute.

\subsection{Measurement of Fat Free Mass}

Fat free mass (FFM) was calculated with the following formula for women, with weight $(\mathrm{W})$ in kilograms and height $(\mathrm{H})$ in centimeters: $\mathrm{FFM}=(0.29569 \times \mathrm{W})+(0.41813 \times \mathrm{H})-$ 43.2933 [42,43]. To measure body fat percentage, seven subcutaneous fat thicknesses were used by the Jackson and Pollock method [44-46]. Seven points were included: triceps, chest, subscapular, suprailiac, axilla, abdominal, and thigh [47]. Data were collected by Lafayette Instrument Company (Lafayette, IN, USA) with an accuracy of $0.1 \mathrm{~mm}$. All measurements were performed by one person on the right side of the body. The person who took the skinfold measurements had taken several skinfold measurements over many years [48-50]. The technical measurement error was considered according to previous studies [51,52].

\subsection{Measurement of Cardio-Respiratory Fitness}

$\mathrm{VO}_{2 \max }$ was measured by $20-\mathrm{m}$ shuttle-run test. The maximum field test consisted of reciprocating runs between two lines $20 \mathrm{~m}$ apart at a speed adjusted to a pre-recorded audible alarm [53]. The initial speed set to start the test was $8.5 \mathrm{~km} / \mathrm{h}^{-1}$, which was increased to $0.5 \mathrm{~km} / \mathrm{h}^{-1}$ after each minute. Participants were instructed to continue the test to the last step as much as possible. The test ended when the person could not keep up with the running speed, or when the person was unable to reach the 20-m area within each lane three times in a row in accordance with the audible warning. The velocity obtained during the last step that was fully performed was considered as the maximum test velocity, and was calculated as $\mathrm{VO}_{2 \max }$ by placing it in the following formula [41]: $\mathrm{VO}_{2 \max }$ $\left(\mathrm{mL} \cdot \mathrm{kg}^{-1} \cdot \mathrm{min}^{-1}\right)=6(\mathrm{x})-24.4 \mathrm{X}$. X is the maximum aerobic speed, which is determined by the running speed at the highest level [54].

\subsection{Measurement of Blood Samples}

To measure IgA and IgG $24 \mathrm{~h}$ before and $24 \mathrm{~h}$ after the study period, $10 \mathrm{~mL}$ blood samples were taken from the left vein of the participants between 9:00 and 11:00 in the morning, blood samples were collected into pipes containing solution of acidic anticoagulant EDTA K2, and, after plasma centrifugation, their plasma was separated, where the resulting plasma was kept at $-20^{\circ} \mathrm{C}$. IgA and IgG concentrations were measured by using Hitachi device, laboratory turbidometry, and Pars test kits. The turbidometry method is based on a complex formation resulting from the reaction between immunoglobulins and its specific antiserum. The amount of turbidity generated is directly related to the amount of immunoglobulins. The minimum volume required to measure $\operatorname{IgG}$ and $\operatorname{IgA}$ by a turbidometric device is $50 \mu \mathrm{L}$.

\subsection{Exercise Protocol}

Participants participated in HIIT exercises three times a week for 8 weeks, with an intensity of $90 \%$ of maximum heart rate. Exercises started from $24 \mathrm{~min}$ in the first session (5 to 10 min of warm-up, $30 \mathrm{~s}$ of exercise (running), and $30 \mathrm{~s}$ of active rest (walking), with 4 repetitions and 5 to $10 \mathrm{~min}$ of cool down), and $27 \mathrm{~min}$ in the last session (5 to $10 \mathrm{~min}$ of warm-up, $30 \mathrm{~s}$ of exercise, and $30 \mathrm{~s}$ of active rest, with 7 repetitions and 5 to $10 \mathrm{~min}$ of cool down) [55]. The participants of the two training groups performed the training protocol at a distance of $20 \mathrm{~m}$ according to Glaister et al. [56]. In the round-robin test practice protocol, participants first ran at maximum speed from the starting point (cone 1) to cone 2 in lane 
A. After returning in the opposite direction on route B, they ran $20 \mathrm{~m}$ towards cone 3 with maximum speed, and finally, after returning, they ran again at maximum speed on route $\mathrm{C}$ (cone 1) to complete the distance of $40 \mathrm{~m}$. Participants continued to perform this at maximum speed until the 30-s period of the training protocol ended, and, after a 30-s break, they repeated the training protocol. Exercise progressed by increasing the number of 30-s repetitions from four times in the first and second weeks to five times in the third and fourth weeks, to six times, in the fifth and sixth weeks, and to seven times in the seventh and 8-week of practice, like previous study training protocol [56]. The intensity of training in all stages of the protocol was $90 \%$ of the maximum heart rate. The heart rate was measured by a control instructor using a Polar pacemaker made in Finland, and the maximum predictable heart rate was estimated with the formula of Tanaka $(208-0.7 \times$ age (years)) [57]. All participants participated in the exercises until they were completed. In this study, the participants in the supplement group did not have any regular exercise.

\subsection{Supplementation}

In the present study, spirulina algae powder was prepared from Isfahan Green Agate Company (Isfahan, Iran). The participants in the CG and SG received $6 \mathrm{~g}$ per day of water-soluble spirulina powder half an hour before a meal, and the participants in the $\mathrm{PH}$ received a green coloring food dissolved in water; this was close to other relevant human studies, as they received $8 \mathrm{~g}$ of spirulina per day [58].

\subsection{Statistical Methods}

Data analysis of the present study has been carried out at both descriptive and inferential concentrations. The distribution between the data was also examined by Shapiro-Wilk test. Equality of variance in different groups was also assessed by Levin test. To determine possible group differences pre-training calculated with a one-way analysis of variance (ANOVA), a $2 \times 3$ ANOVA with repeated measures (time [pre- vs. post-training] $\times$ group [CG vs. SG vs. PH]) was used to determine differences between groups, and then we used the suitable Tukey post hoc test when a significant group-by-time interaction was discovered. Hedge's g effect size with $95 \%$ confidence interval was also calculated to determine the magnitude of pairwise comparisons for pre- and post-test, and was defined as trivial $(<0.2)$, small $(\geq 0.02)$, moderate $(\geq 0.05)$, and large $(\geq 0.08)$ [59]. If the results of the one-way ANOVA and effect sizes were similar for each group (i.e., FFM), then the percentage changes were computed and assessed. Significance of statistical analysis was used at the level of $p<0.05$. All statistical calculations were performed using SPSS (Version 25.0; IBM SPSS Inc., Chicago, IL, USA).

\section{Results}

Table 2 shows the mean and standard deviation of the changes in $\mathrm{VO}_{2 \max }, \operatorname{Ig} \mathrm{A}$, and IgG. At the baseline, there were no differences observed between groups in the above variables $(p>0.05)$. There was no significant main effect of time for $\operatorname{IgA}(p=0.073, \mathrm{f}=3.48$, $\left.\eta \mathrm{p}^{2}=0.11\right)$; however, there was a meaningful group-by-time interaction $(p=0.036, \mathrm{f}=3.86$, $\left.\eta p^{2}=0.22\right)$. The post hoc analysis found that $\operatorname{IgA}(\mathrm{CG}, p=0.02, g=0.70$ and SG, $p=0.001$, $g=0.34)$ was significantly greater post-test versus pre-test.

Table 3 shows the mean and standard deviation in the anthropometric and body composition. At the baseline, there were no differences observed between groups in all variables, except the waist-to-hip ratio $(\mathrm{f}=4.39, p<0.02)$. Based on the analysis, there was no significant main effect of time for FFM $\left(p=0.36, \mathrm{f}=0.86, \eta \mathrm{p}^{2}=0.03\right)$, whereas there was a meaningful group-by-time interaction $\left(p=0.001, \mathrm{f}=8.52, \eta p^{2}=0.39\right)$. The post hoc analysis indicated that FFM (kg) (CG, $p=0.012, g=-0.54)$ was significantly reduced. In addition, in the SG group, this variable increased but was not significant $(p>0.05)$. However, there were significant main effects of time for the rest of the variables, but there were no significant group-by-time interactions for changes in these variables. 
Table 2. Changes in $\mathrm{VO}_{2 \max }$ and immunoglobulins.

\begin{tabular}{|c|c|c|c|c|c|c|c|}
\hline \multirow{2}{*}{ Variables } & \multirow{2}{*}{ Groups } & \multirow{2}{*}{ Pre-Training } & \multirow{2}{*}{ Post-Training } & \multicolumn{2}{|c|}{ CI 95\% for Difference } & \multirow{2}{*}{ Hedge's g } & \multirow{2}{*}{$\%$ Changes } \\
\hline & & & & Lower & Upper & & \\
\hline \multirow{3}{*}{$\begin{array}{c}\mathrm{VO}_{2 \max } \\
\left({\mathrm{mL} \cdot \mathrm{kg}^{-1}}^{\left.\min ^{-1}\right)}\right.\end{array}$} & $\mathrm{PH}$ & $21.8 \pm 3.4$ & $23.4 \pm 1.8$ & -4.21 & 0.93 & 0.57 & 9.21 \\
\hline & $C G$ & $23.2 \pm 2.1$ & $25.6 \pm 3.1$ & -4.85 & 0.05 & 0.88 & 11.03 \\
\hline & $S G$ & $21.3 \pm 1.9$ & $21.9 \pm 3.0$ & -2.91 & 1.73 & 0.23 & 2.58 \\
\hline \multirow{3}{*}{$\underset{\text { (mg/lit) }}{\operatorname{IgA}}$} & $\mathrm{PH}$ & $161.7 \pm 86.2$ & $149.2 \pm 50.8$ & -53.97 & 78.97 & -0.16 & -2.31 \\
\hline & $C G$ & $173.1 \pm 33.7$ & $212.7 \pm 67.8^{*}$ & -89.90 & 10.70 & 0.70 & 21.23 \\
\hline & $S G$ & $171.1 \pm 47.9$ & $187.5 \pm 44.6^{*}$ & -59.86 & 27.06 & 0.33 & 11.82 \\
\hline \multirow{3}{*}{$\begin{array}{c}\text { IgG } \\
\text { (mg/lit) }\end{array}$} & PH & $1253.5 \pm 413.6$ & $1227.1 \pm 316.1$ & -319.46 & 372.26 & -0.06 & -3.21 \\
\hline & $C G$ & $1309.3 \pm 285.3$ & $1461.5 \pm 240.1$ & -399.91 & 95.51 & 0.55 & 13.28 \\
\hline & $S G$ & $1301.0 \pm 317.8$ & $1460.4 \pm 272.2$ & -437.38 & 118.58 & 0.51 & 14.17 \\
\hline
\end{tabular}

Abbreviation: $\mathrm{VO}_{2 \max }=$ maximum oxygen consumption; $\mathrm{IgA}=$ immunoglobulin $\mathrm{A} ; \mathrm{IgG}=$ immunoglobulin $\mathrm{G}$ $\mathrm{HIIT}=$ high-intensity interval training; $\mathrm{CI}=$ confidence interval; $\mathrm{PH}=$ placebo and HIIT; $\mathrm{CG}=$ combined group $\mathrm{SG}=$ spirulina group. ${ }^{*}$ to reflect significance pre- vs. post-test at the level of $p<0.05$.

Table 3. Changes in anthropometric and body composition.

\begin{tabular}{|c|c|c|c|c|c|c|c|}
\hline \multirow{2}{*}{ Variables } & \multirow{2}{*}{ Groups } & \multirow{2}{*}{ Pre-Training } & \multirow{2}{*}{ Post-Training } & \multicolumn{2}{|c|}{ CI $95 \%$ for Difference } & \multirow{2}{*}{ Hedge's g } & \multirow{2}{*}{$\%$ Changes } \\
\hline & & & & Lower & Upper & & \\
\hline \multirow{3}{*}{$\begin{array}{c}\text { BMI } \\
\left(\mathrm{kg} / \mathrm{m}^{2}\right)\end{array}$} & $\mathrm{PH}$ & $27.6 \pm 1.9$ & $26.3 \pm 1.9$ & -0.48 & 3.08 & -0.65 & -4.64 \\
\hline & $C G$ & $28.8 \pm 4.3$ & $27.7 \pm 4.6$ & -3.08 & 5.26 & -0.23 & -3.92 \\
\hline & $S G$ & $29.9 \pm 4.0$ & $29.6 \pm 4.1$ & -3.49 & 4.09 & -0.07 & -1.06 \\
\hline \multirow{3}{*}{$\begin{array}{l}\text { WHR } \\
(\mathrm{cm})\end{array}$} & $\mathrm{PH}$ & $0.80 \pm 0.05$ & $0.79 \pm 0.06$ & -0.04 & 0.06 & -0.17 & -1.15 \\
\hline & $C G$ & $0.73 \pm 0.03$ & $0.72 \pm 0.03$ & -0.01 & 0.03 & -0.31 & -1.79 \\
\hline & $S G$ & $0.88 \pm 0.18$ & $0.80 \pm 0.09$ & -0.05 & 0.21 & -0.53 & -6.74 \\
\hline \multirow{3}{*}{$\begin{array}{l}\text { Body mass } \\
(\text { kg) }\end{array}$} & $P H$ & $73.3 \pm 5.3$ & $70.2 \pm 4.0$ & -1.33 & 7.45 & -0.62 & -4.03 \\
\hline & $C G$ & $76.7 \pm 11.1$ & $74.1 \pm 11.1$ & -7.83 & 13.01 & -0.22 & -3.40 \\
\hline & $S G$ & $77.3 \pm 8.9$ & $76.1 \pm 10.0$ & -7.64 & 10.10 & -0.12 & -1.73 \\
\hline \multirow{3}{*}{$\begin{array}{c}\text { FFM } \\
(\mathrm{kg})\end{array}$} & $\mathrm{PH}$ & $19.5 \pm 2.1$ & $19.1 \pm 2.4$ & -1.76 & 2.46 & -0.14 & -1.89 \\
\hline & $C G$ & $18.8 \pm 0.8$ & $18.3 \pm 0.96 *$ & -0.32 & 1.36 & -0.54 & -2.76 \\
\hline & $S G$ & $19.7 \pm 2.3$ & $20.1 \pm 2.1$ & -2.47 & 1.67 & 0.17 & 2.22 \\
\hline \multirow{3}{*}{ BF (\%) } & PH & $31.7 \pm 3.0$ & $30.4 \pm 3.0$ & -1.39 & 4.09 & -0.43 & -4.20 \\
\hline & $C G$ & $32.0 \pm 2.4$ & $31.0 \pm 3.0$ & -1.48 & 3.62 & -0.37 & -3.43 \\
\hline & $S G$ & $33.9 \pm 3.9$ & $31.3 \pm 2.9$ & -0.64 & 5.82 & -0.71 & -7.29 \\
\hline
\end{tabular}

Abbreviation: $\mathrm{BMI}=$ body mass index; $\mathrm{WHR}=$ waist-hip ratio; $\mathrm{FFM}=$ free fat mass; $\mathrm{BF} \%$ = body fat percentage $\mathrm{HIIT}=$ high-intensity interval training; $\mathrm{CI}=$ confidence interval; $\mathrm{PH}=$ placebo and $\mathrm{HIIT} ; \mathrm{CG}=$ combined group spirulina and HIIT; SG = spirulina group. ${ }^{*}$ to reflect significance pre- vs. post-test at the level of $p<0.05$.

\section{Discussion}

Our purpose was to examine the effect of 8-week HIIT and spirulina supplementation on the humoral immune function, cardio-respiratory fitness, and body composition of overweight and obese women. We found that 8-week HIIT with $6 \mathrm{~g}$ of spirulina supplementation per day significantly improved IgA (CG: $212.7 \pm 67.8$ and SG: $187.5 \pm 44.6$ ) compared to the baseline (CG: $173.1 \pm 33.7$ and SG: $171.1 \pm 47.9)$ and FFM $(18.3 \pm 1.0)$ compared to the baseline ( $18.8 \pm 0.8)$ in CG. Although IgG did not change significantly, the percentage change in the spirulina groups was illustrated as being between 13 to $15 \%$, with a medium-to-high effect size. The study of Jahani et al. [60] that examined the effect of HIIT and probiotic supplementation on immune cells, C-reactive protein, and IgA showed that intense intermittent exercise increases IgA, which is consistent with the results of the present study. Spirulina has a powerful stimulatory effect on the immune system through increasing the phagocytic activity of macro-phages, inducing the accumulation of natural killers cells in tissues, stimulating antibody and cytokine production, and activating and mobilizing T or B cells [61]. Previous studies demonstrated that spirulina diminishes the negative effect of different agents of Ig concentrations $[62,63]$ and leukocyte numbers [64]. 
The researchers concluded that exercise-induced changes in serum Ig concentrations may be due to the participation of extravascular proteins, increased lymphocytes after exercise, a combination of changes in the plasma volume and extravascular flow, and changes in the subject's circadian cycle [65]. Factors involved in immunity include sex, age, race, smoking, strenuous or moderate physical activity, alcohol consumption, obesity, pregnancy, hormonal factors, and common microflora in each individual's digestive tract $[66,67]$. Therefore, one of the factors involved in the difference between the results of other studies and the findings of the present study can be enumerated in environmental and genetic factors that were beyond the control of the researchers [68]. Saeedy et al. [31] showed that HIIT, along with zinc supplementation, significantly improved IgA. Qieqeshlaq et al. [68] showed that HIIT and probiotic increased IgA significantly. Spirulina has a hypolipidemic activity and decreases the concentrations of liver profiles [69].

Mohebi et al. [70] showed that 8-week high-intensity resistance training decreased IgG concentration significantly in untrained men. The contradiction with the present study may be due to the difference between detailed training and participants. Santoso et al. [71] showed that there was a change between the IgG level of pre- and post-test of breathing arts sports treatment, and that this change increased significantly after the respiratory exercise. Although the IgG concentrations did not alter considerably, the spirulina groups showed a percentage change of 13 to $15 \%$ with a medium to large effect size. The phycocyanin in spirulina increases biological activity against infectious diseases by maintaining the function of the mucosal immune system and reducing allergic inflammation by suppressing specific antibodies, and injecting it produces IgA antibodies. Spirulina polysaccharide also activates innate immune cells and increases antibodies [72]. The polysaccharides and phycocyanins in spirulina help to both increase the number of antigens through physical activity and increase the immune system. Therefore, intense intermittent exercise with spirulina supplementation has a greater effect on strengthening the immune system [73,74].

Spirulina supplementation decreased the FFM of overweight and obese women significantly. Hunter et al. showed that, after 4 weeks of resistance training, the amount of FFM decreased significantly [75]. The results of their research is consistent with our results, which is probably due to the similar training duration [76].

Our present study had some limitations. We did not control the participants' diets. Furthermore, we could have had a longer duration for our study. In addition, by observing large percentage changes in the variable of IgG, we did not see significant changes, which was probably due to individual effects and large changes in some participants. We strongly recommend that individual differences, resting energy expenditure, physical activity levels, and dietary intake be considered in future studies. Additionally, more studies with different ages, as well as with women and men, may help to delineate the effects of HIIT and spirulina supplementation on the immune function, body composition, and exercise performance. Finally, another limitation of the study could be the field training protocol that has been performed. This could be considered in future studies by increasing the control of the training intensity with heart rate and considering the session calibration of the device used.

\section{Conclusions}

In this study, the effect of an 8-week period of HIIT combined with spirulina supplementation on the humoral immune system and body composition of overweight and obese women was investigated. The data in the present study demonstrated the effectiveness of spirulina supplementation and HIIT concurrently in making significant changes in IgA concentrations and FFM. Taking spirulina with HIIT for overweight and obese women may be helpful not only for losing FFM but also for boosting IgA, which plays an important role in the immune system.

Author Contributions: Conceptualization, E.E.G., H.N. and J.R.; methodology, E.E.G., H.N., R.V. and J.R.; software, H.N., S.L.V. and R.V.; interpretation of data, H.N. and R.V., critical revision, H.N., J.P.-G. and K.S.; revised manuscript, R.V., S.L.V. and H.N., writing-original draft preparation, H.N., R.V. 
and E.E.G.; writing - review and editing, H.N., K.S. and S.L.V. All authors have read and agreed to the published version of the manuscript.

Funding: There is no external funding.

Institutional Review Board Statement: The study has been approved by the Ethics Committee of the University of Isfahan IR.UI.REC.1397.145.

Informed Consent Statement: Informed consent was obtained from all participants involved in the study.

Data Availability Statement: The datasets used and/or analyzed during the current study are available from the corresponding author on reasonable request.

Conflicts of Interest: The authors declare no conflict of interest.

\section{References}

1. WHO. Obesity: Preventing and Managing the Global Epidemic. Report of a WHO Consultation; World Health Organization Technical Report Series nr 894; WHO: Geneva, Switzerland, 2000; pp. 1-253.

2. WHO Expert Consultation. Appropriate body-mass index for Asian populations and its implications for policy and intervention strategies. Lancet 2004, 363, 157-163. [CrossRef]

3. Huttunen, R.; Syrjänen, J. Obesity and the risk and outcome of infection. Int. J. Obes. Lond. 2013, 37, 333-340. [CrossRef] [PubMed]

4. Kanneganti, T.-D.; Dixit, V.D. Immunological complications of obesity. Nat. Immunol. 2012, 13, 707-712. [CrossRef] [PubMed]

5. Kaspersen, K.A.; Pedersen, O.B.; Petersen, M.S.; Hjalgrim, H.; Rostgaard, K.; Møller, B.K.; Juul-Sørensen, C.; Kotzé, S.; Dinh, K.M.; Erikstrup, L.T.; et al. Obesity and risk of infection: Results from the Danish Blood Donor Study. Epidemiology 2015, 26, 580-589. [CrossRef] [PubMed]

6. Miranda, M.; Cintra, R.; Barros, S.; Mancini-Filho, J. Antioxidant activity of the microalga Spirulina maxima. Braz. J. Med. Biol. Res. 1998, 31, 1075-1079. [CrossRef] [PubMed]

7. Deng, R.; Chow, T.-J. Hypolipidemic, Antioxidant, and Antiinflammatory Activities of Microalgae Spirulina. Cardiovasc. Ther. 2010, 28, e33-e45. [CrossRef] [PubMed]

8. Milasius, K.; Malickaite, R.; Dadeliene, R. Effect of spirulina food supplement on blood morphological parameters, biochemical composition and on the immune function of sportsmen. Biol. Sport 2009, 26, 157-172. [CrossRef]

9. Hernández-Lepe, M.A.; Olivas-Aguirre, F.J.; Gómez-Miranda, L.M.; Hernández-Torres, R.P.; Manríquez-Torres, J.J.; Ramos-Jiménez, A. Systematic physical exercise and Spirulina maxima supplementation improve body composition, cardiorespiratory fitness, and blood lipid profile: Correlations of a randomized double-blind controlled trial. Antioxidants 2019, 8, 507. [CrossRef]

10. Thengodkar, R.R.M.; Sivakami, S. Degradation of chlorpyrifos by an alkaline phosphatase from the cyanobacterium Spirulina platensis. Biodegradation 2010, 21, 637-644. [CrossRef]

11. Ramírez-Rodrigues, M.M.; Estrada-Beristain, C.; Metri-Ojeda, J.; Pérez-Alva, A.; Baigts-Allende, D.K. Spirulina platensis Protein as Sustainable Ingredient for Nutritional Food Products Development. Sustainability 2021, 13, 6849. [CrossRef]

12. Wu, Q.; Liu, L.; Miron, A.; Klímová, B.; Wan, D.; Kuča, K. The antioxidant, immunomodulatory, and anti-inflammatory activities of Spirulina: An overview. Arch. Toxicol. 2016, 90, 1817-1840. [CrossRef]

13. Zovko Koncic, M.; Tomczyk, M. New insights into dietary supplements used in sport: Active substances, pharmacological and side effects. Curr. Drug Targets 2013, 14, 1079-1092. [CrossRef]

14. Hernández-Lepe, M.A.; López-Díaz, J.A.; Juárez-Oropeza, M.A.; Hernández-Torres, R.P.; Wall-Medrano, A.; Ramos-Jiménez, A. Effect of Arthrospira (Spirulina) maxima supplementation and a systematic physical exercise program on the body composition and cardiorespiratory fitness of overweight or obese subjects: A double-blind, randomized, and crossover controlled trial. Mar. Drugs 2018, 16, 364. [CrossRef]

15. Clark, T.; Morey, R.; Jones, M.D.; Marcos, L.; Ristov, M.; Ram, A.; Hakansson, S.; Franklin, A.; McCarthy, C.; De Carli, L.; et al. High-intensity interval training for reducing blood pressure: A randomized trial vs. moderate-intensity continuous training in males with overweight or obesity. Hypertens. Res 2020, 43, 396-403. [CrossRef]

16. Francois, M.E.; Little, J.P. Effectiveness and safety of high-intensity interval training in patients with type 2 diabetes. Diabetes Spectr. 2015, 28, 39-44. [CrossRef]

17. Gibala, M.J.; Little, J.P.; MacDonald, M.J.; Hawley, J.A. Physiological adaptations to low-volume, high-intensity interval training in health and disease. J. Physiol. 2012, 590, 1077-1084. [CrossRef]

18. D'Amuri, A.; Sanz, J.M.; Capatti, E.; Di Vece, F.; Vaccari, F.; Lazzer, S.; Zuliani, G.; Nora, E.D.; Passaro, A. Effectiveness of high-intensity interval training for weight loss in adults with obesity: A randomised controlled non-inferiority trial. BMJ Open Sport Exerc. Med. 2021, 7, e001021. [CrossRef]

19. Nobari, H.; Ahmadi, M.; Sá, M.; Pérez-Gómez, J.; Clemente, F.M.; Adsuar, J.C.; Minasian, V.; Afonso, J. The effect of two types of combined training on bio-motor ability adaptations in sedentary females. J. Sports Med. Phys. Fit. 2021, 61, 1317-1325. [CrossRef] 
20. Jurio-Iriarte, B.; Maldonado-Martín, S. Effects of different exercise training programs on cardiorespiratory fitness in overweight/obese adults with hypertension: A pilot study. Health Promot. Pract. 2019, 20, 390-400. [CrossRef]

21. Sculthorpe, N.F.; Herbert, P.; Grace, F. One session of high-intensity interval training (HIIT) every 5 days, improves muscle power but not static balance in lifelong sedentary ageing men: A randomized controlled trial. Medicine 2017, 96, e6040. [CrossRef]

22. Batacan, R.B.; Duncan, M.J.; Dalbo, V.J.; Tucker, P.S.; Fenning, A.S. Effects of high-intensity interval training on cardiometabolic health: A systematic review and meta-analysis of intervention studies. Br. J. Sports Med. 2017, 51, 494-503. [CrossRef]

23. Khammassi, M.; Ouerghi, N.; Hadj-Taieb, S.; Feki, M.; Thivel, D.; Bouassida, A. Impact of a 12-week high-intensity interval training without caloric restriction on body composition and lipid profile in sedentary healthy overweight/obese youth. J. Exerc. Rehabil. 2018, 14, 118-125. [CrossRef]

24. Ribeiro, R.L.; de Oliveira Silva, J.I.; Dantas, M.G.B.; Menezes, E.S.; Arruda, A.; Schwingel, P. High-intensity interval training applied in Brazilian Jiu-jitsu is more effective to improve athletic performance and body composition. J. Combat Sports Martial Arts 2015, 6, 1-5. [CrossRef]

25. Gillen, J.B.; Percival, M.E.; Ludzki, A.; Tarnopolsky, M.A.; Gibala, M.J. Interval training in the fed or fasted state improves body composition and muscle oxidative capacity in overweight women. Obesity 2013, 21, 2249-2255. [CrossRef]

26. Andreato, L.; Esteves, J.V.; Coimbra, D.R.; Moraes, A.J.P.; de Carvalho, T. The influence of high-intensity interval training on anthropometric variables of adults with over-weight or obesity: A systematic review and network meta-analysis. Obes. Rev. 2019, 20, 142-155. [CrossRef]

27. Shirvani, H.; Ghahreman Tabrizi, K.; Sobhani, V. Effects of high intensity intermittent exercise on serum Immunoglobulin's and Complement system response in youth soccer players. J. Birjand Univ. Med. Sci. 2013, 20, 233-243.

28. Rahimi, R.; Ghaderi, M.; Mirzaei, B.; Ghaeni, S.; Faraji, H.; Vatani, D.S.; Rahmani-Nia, F. Effects of very short rest periods on immunoglobulin A and cortisol responses to resistance exercise in men. J. Hum. Sport Exerc. 2010, 5, 146-157. [CrossRef]

29. Lira, F.S.; Yamashita, A.S.; Uchida, M.C.; Zanchi, N.E.; Gualano, B.; Martins, E.; Caperuto, E.C.; Seelaender, M. Low and moderate, rather than high intensity strength exercise induces benefit regarding plasma lipid profile. Diabetol. Metab. Syndr. $2010,2,31$. [CrossRef]

30. Azarbayjani, M.A.; Nikbakht, H. The effect of continuous and intermittent training on resting level and acute response of salivary $\operatorname{IgA}$ and total protein in male basketball players. J. Shahrekord Univ. Med. Sci. 2010, 12, 1-11.

31. Saeedy, M.; Bijeh, N.; Moazzami, M. The effect of six weeks of high-intensity interval training with Zinc supplementation on some humoral immunity markers in female futsal players. Ann. Appl. Sport Sci. 2018, 6, 11-19. [CrossRef]

32. Nobari, H.; Saedmocheshi, S.; Chung, L.H.; Suzuki, K.; Maynar-Mariño, M.; Pérez-Gómez, J. An Overview on How Exercise with Green Tea Consumption Can Prevent the Production of Reactive Oxygen Species and Improve Sports Performance. Int. J. Env. Res. Public Health 2021, 19, 218. [CrossRef] [PubMed]

33. Zwetsloot, K.A.; John, C.S.; Lawrence, M.M.; Battista, R.A.; Shanely, R.A. High-intensity interval training induces a modest systemic inflammatory response in active, young men. J. Inflamm. Res. 2014, 7, 9-17. [CrossRef] [PubMed]

34. Owen, A.L.; Wong, D.P.; Dunlop, G.; Groussard, C.; Kebsi, W.; Dellal, A.; Morgans, R.; Zouhal, H. High-intensity training and salivary immunoglobulin a responses in professional top-level soccer players: Effect of training intensity. J. Strength Cond. Res. 2016, 30, 2460-2469. [CrossRef] [PubMed]

35. Lee, N.; Kim, J.; Hyung, G.A.; Park, J.H.; Kim, S.J.; Kim, H.B.; Jung, H.S. Training effects on immune function in judoists. Asian J. Sports Med. 2015, 6, e24050. [CrossRef]

36. Oyeyinka, G.; Salimonu, L.S.; Williams, A.I.; Johnson, A.O.; Ladipo, O.A.; Osunkoya, B.O. Range of normal serum immunoglobulin (IgG, IgA and IgM) values in Nigerians. Afr. J. Med. Med Sci. 1984, 13, 169-176.

37. Bayram, R.O.; Özdemir, H.; Emsen, A.; Türk Dağ1, H.; Artaç, H. Reference ranges for serum immunoglobulin (IgG, IgA, and IgM) and IgG subclass levels in healthy children. Turk. J. Med. Sci. 2019, 49, 497-505. [CrossRef]

38. Kalafati, M.; Jamurtas, T.; Nikolaidis, M.G.; Paschalis, V.; Theodorou, A.A.; Sakellariou, G.K.; Koutedakis, Y.; Kouretas, D Ergogenic and antioxidant effects of spirulina supplementation in humans. Med. Sci. Sports Exerc. 2010, 42, 142-151. [CrossRef]

39. Faelli, E.; Bisio, A.; Codella, R.; Ferrando, V.; Perasso, L.; Panascì, M.; Saverino, D.; Ruggeri, P. Acute and Chronic Catabolic Responses to CrossFit ${ }^{\circledR}$ and Resistance Training in Young Males. Int. J. Environ. Res. Public Health 2020, 17, 7172. [CrossRef]

40. Codella, R.; Chirico, A.; Lucidi, F.; Ferrulli, A.; La Torre, A.; Luzi, L. The immune-modulatory effects of exercise should be favorably harnessed against COVID-19. J. Endocrinol. Investig. 2021, 44, 1119-1122. [CrossRef]

41. Gibson, A.S.C.; Broomhead, S.; Lambert, M.; Hawley, J. Prediction of maximal oxygen uptake from a 20-m shuttle run as measured directly in runners and squash players. J. Sports Sci. 1998, 16, 331-335. [CrossRef]

42. Pearce, C. Is Using a Patient's Estimated Lean Body Mass a Suitable Method of Predicting Their Eventual Therapeutic Units of Botulinum Toxin for the Treatment of Cervical Dystonia? 2016. Available online: https://rde.dspace-express $\mathrm{com} /$ bitstream/handle/11287/610852/Is+using+a+patient\%20s+lean+body+mass+a+suitable+method+of+predicting+their+ eventual+therapeutic+dose+of+botulinum+toxin+for+the+treatment+of+cervical+dystonia.pdf?sequence $=2$ (accessed on 16 December 2021).

43. Hume, R. Prediction of lean body mass from height and weight. J. Clin. Pathol. 1966, 19, 389-391. [CrossRef]

44. Nobari, H.; Silva, A.F.; Clemente, F.M.; Siahkouhian, M.; García-Gordillo, M.Á.; Adsuar, J.C.; Pérez-Gómez, J. Analysis of fitness status variations of Under-16 soccer players over a season and their relationships with maturational status and training load. Front. Physiol. 2021, 11, 1840. [CrossRef] 
45. Nobari, H.; Cholewa, J.M.; Pérez-Gómez, J.; Castillo-Rodríguez, A. Effects of 14-weeks betaine supplementation on proinflammatory cytokines and hematology status in professional youth soccer players during a competition season: A double blind, randomized, placebo-controlled trial. J. Int. Soc. Sports Nutr. 2021, 18, 42. [CrossRef]

46. Jackson, A.S.; Pollock, M.L.; Ward, A. Generalized equations for predicting body density of women. Med. Sci. Sports Exerc. 1980, 12, 175-181. [CrossRef]

47. Wagner, D.R. Ultrasound as a tool to assess body fat. J. Obes. 2013, 2013, 280713. [CrossRef]

48. Arazi, H.; Mirzaei, B.; Nobari, H. Anthropometric profile, body composition and somatotyping of national Iranian cross-country runners. Turk. J. Sport Exerc. 2015, 17, 35-41. [CrossRef]

49. Rahmat, A.J.; Arsalan, D.; Bahman, M.; Hadi, N. Anthropometrical profile and bio-motor abilities of young elite wrestlers. Phys. Educ. Stud. 2016, 20, 63-69. [CrossRef]

50. Wannamethee, S.G.; Shaper, A.G.; Whincup, P.H. Body fat distribution, body composition, and respiratory function in elderly men. Am. J. Clin. Nutr. 2005, 82, 996-1003. [CrossRef]

51. Nobari, H.; Alves, A.R.; Clemente, F.M.; Pérez-Gómez, J.; Clark, C.C.T.; Granacher, U.; Zouhal, H. Associations between variations in accumulated workload and physiological variables in young male soccer players over the course of a season. Front. Physiol. 2021, 12, 233. [CrossRef]

52. Nobari, H.; Aquino, R.; Clemente, F.M.; Khalafi, M.; Adsuar, J.C.; Pérez-Gómez, J. Description of acute and chronic load, training monotony and strain over a season and its relationships with well-being status: A study in elite under-16 soccer players. Physiol. Behav. 2020, 225, 113117. [CrossRef]

53. Jafari, M.; Pouryamehr, E.; Fathi, M. The effect of eight weeks high intensity interval training (HIIT) on E-selection and P-selection in young obese females. Int. J. Sport Stud. Health 2018, 1, e64336. [CrossRef]

54. Kilding, A.E.; Aziz, A.R.; Teh, K. Measuring and predicting maximal aerobic power in international-level intermittent sport athletes. J. Sports Med. Phys. Fit. 2006, 46, 366.

55. Bahram, M.E.; Mogharnasi, M. The Effect of Twelve weeks High Intensity Training Interval (HIIT) on Leptin Levels and Obesity Dependent Factors among Female Students Suffering Overweight. J. Sport Biosci. 2015, 6, 451-465.

56. Glaister, M.; Hauck, H.; Abraham, C.S.; Merry, K.L.; Beaver, D.; Woods, B.; McInnes, G. Familiarization, reliability, and comparability of a 40-m maximal shuttle run test. J. Sports Sci. Med. 2009, 8, 77.

57. Camarda, S.R.d.A.; Tebexreni, A.S.; Páfaro, C.N.; Sasai, F.B.; Tambeiro, V.L.; Juliano, Y.; de Barros Neto, T.L. Comparison of maximal heart rate using the prediction equations proposed by Karvonen and Tanaka. Arq. Bras. Cardiol. 2008, 91, 311-314. [CrossRef]

58. Nobari, H.; Fashi, M.; Eskandari, A.; Pérez-Gómez, J.; Suzuki, K. Potential Improvement in Rehabilitation Quality of 2019 Novel Coronavirus by Isometric Training System; Is There "Muscle-Lung Cross-Talk"? Int. J. Environ. Res. Public Health 2021, 18, 6304. [CrossRef]

59. Hopkins, B.; Cole, B.L.; Mason, T.L. A critique of the usefulness of inferential statistics in applied behavior analysis. Behav. Anal. 1998, 21, 125-137. [CrossRef]

60. Jahani, Q.G.R.; Abkar, A.R.; Heidari, H. The Effect of High-Intensity Intermittent Training (HIIT) and Consumption of Probiotic Supplement on Immune Cells, C-Reactive Protein, and IgA in Young Football Player. Qom Univ. Med. Sci. J. 2016, 10, 36-46.

61. Khafaga, A.F.; El-Sayed, Y.S. Spirulina ameliorates methotrexate hepatotoxicity via antioxidant, immune stimulation, and proinflammatory cytokines and apoptotic proteins modulation. Life Sci. 2018, 196, 9-17. [CrossRef]

62. Hayashi, O.; Hirahashi, T.; Katoh, T.; Miyajima, H.; Hirano, T.; Okuwaki, Y. Class specific influence of dietary Spirulina platensis on antibody production in mice. J. Nutr. Sci. Vitaminol. 1998, 44, 841-851. [CrossRef] [PubMed]

63. Tominaga, A.; Konishi, Y.; Taguchi, T.; Fukuoka, S.; Kawaguchi, T.; Noda, T.; Shimizu, K. Autonomous cure of damaged human intestinal epithelial cells by TLR2 and TLR4-dependent production of IL-22 in response to Spirulina polysaccharides. Int. Immunopharmacol. 2013, 17, 1009-1019. [CrossRef] [PubMed]

64. Uzar, E.; Sahin, O.; Koyuncuoglu, H.R.; Uz, E.; Bas, O.; Kilbas, S.; Yilmaz, H.R.; Yurekli, V.A.; Kucuker, H.; Songur, A. The activity of adenosine deaminase and the level of nitric oxide in spinal cord of methotrexate administered rats: Protective effect of caffeic acid phenethyl ester. Toxicology 2006, 218, 125-133. [CrossRef] [PubMed]

65. Leicht, C.A.; Goosey-Tolfrey, V.L.; Bishop, N.C. Exercise intensity and its impact on relationships between salivary immunoglobulin A, saliva flow rate and plasma cortisol concentration. Eur. J. Appl. Physiol. 2018, 118, 1179-1187. [CrossRef] [PubMed]

66. De Souza, D.C.; Matos, V.; Dos Santos, V.O.A.; Medeiros, I.F.; Marinho, C.S.R.; Nascimento, P.R.P.; Dorneles, G.P.; Peres, A.; Müller, C.H.; Krause, M.; et al. Effects of High-Intensity Interval and Moderate-Intensity Continuous Exercise on Inflammatory, Leptin, IgA, and Lipid Peroxidation Responses in Obese Males. Front. Physiol. 2018, 9, 567. [CrossRef] [PubMed]

67. Nobari, H.; Nejad, H.; Kargarfard, M.; Mohseni, S.; Suzuki, K.; Adsuar, J.C.; Pérez-Gómez, J. The Effect of Acute Intense Exercise on Activity of Antioxidant Enzymes in Smokers and Non-Smokers. Biomolecules 2021, 11, 171. [CrossRef]

68. Nobari, H.; Kargarfard, M.; Minasian, V.; Cholewa, J.M.; Pérez-Gómez, J. The effects of 14-week betaine supplementation on endocrine markers, body composition and anthropometrics in professional youth soccer players: A double blind, randomized, placebo-controlled trial. J. Int. Soc. Sports Nutr. 2021, 18, 20. [CrossRef] 
69. Szulinska, M.; Gibas-Dorna, M.; Miller-Kasprzak, E.; Suliburska, J.; Miczke, A.; Walczak-Gałezewska, M.; Stelmach-Mardas, M.; Walkowiak, J.; Bogdanski, P. Spirulina maxima improves insulin sensitivity, lipid profile, and total antioxidant status in obese patients with well-treated hypertension: A randomized double-blind placebo-controlled study. Eur. Rev. Med. Pharm. Sci. 2017, $21,2473-2481$.

70. Mohebbi, H.; Azizi, M.; Moradiani, H. Effect of 8 weeks low and high intensity resistance training on leukocyte count, Igg, cortisol and lactate concentration in untrained men. World Appl. Sci. J. 2012, 16, 949-954.

71. Santoso, D.A.; Asnar, E. Changes of Interleukin-6 (IL-6) and Immunoglobulin G (igG) in Respiratory Excercise. Indian J. Forensic Med. Toxicol. 2020, 14, 1501-1506.

72. Chu, W.-L.; Van Quynh, L.; Radhakrishnan, A.K. Effect of Spirulina (Arthrospira) supplementation on the immune response to tetanus toxoid vaccination in a mouse model. J. Diet. Suppl. 2013, 10, 229-240. [CrossRef]

73. Seyidoglu, N.; Inan, S.; Aydin, C. A Prominent Superfood: Spirulina platensis. In Superfood Functional Food. The Development of Superfoods Their Roles as Medicine; Shiomi, N., Ed.; InTechOpen: London, UK, 2017; pp. 1-27.

74. Ötleş, S.; Pire, R. Fatty acid composition of Chlorella and Spirulina microalgae species. J. AOAC Int. 2001, 84, 1708-1714. [CrossRef] [PubMed]

75. Hunter, G.R.; Fisher, G.; Neumeier, W.H.; Carter, S.J.; Plaisance, E.P. Exercise training and energy expenditure following weight loss. Med. Sci. Sports Exerc. 2015, 47, 1950. [CrossRef] [PubMed]

76. Vella, C.A.; Taylor, K.; Drummer, D. High-intensity interval and moderate-intensity continuous training elicit similar enjoyment and adherence levels in overweight and obese adults. Eur. J. Sport Sci. 2017, 17, 1203-1211. [CrossRef] [PubMed] 